\title{
The association between obesity and blood pressure in Thai public school children
}

\author{
Penmat Sukhonthachit ${ }^{1}$, Wichai Aekplakorn², Chatrapa Hudthagosol ${ }^{1}$ and Chutima Sirikulchayanonta ${ }^{1 *}$
}

\begin{abstract}
Background: The prevalence of obesity has substantially increased in the past 3 decades in both developed and developing countries and may lead to an increase in high blood pressure (BP) at an early age. This study aimed to determine the prevalence of obesity and its association with blood pressure among primary school children in central Thailand.

Methods: A cross-sectional study was conducted in two public schools in Bangkok in 2012. A total of 693 students (317 boys and 376 girls) aged 8-12 years participated voluntarily. Anthropometric measurements of weight, height, waist circumference (WC) and BP were collected. Fasting venous blood samples were obtained for biochemical analysis of fasting plasma glucose (FPG) and lipid parameters. Child nutritional status was defined by body mass index (BMI) for age based on the 2000 Center for Diseases Control and Prevention growth charts. The cutoff for abdominal obesity was WC at the 75 percentile or greater. Hypertension was defined according to the 2004 Pediatrics US blood pressure reference. Multinomial logistic regression was used to examine the relationship between high BP and obesity after controlling for other covariates.

Results: The prevalence of obese children was 30.6\% for boys and 12.8\% for girls (mean prevalence 20.9\%). Pre-hypertension (Pre-HT) was 5.7\% and 2.7\% for boys and girls and hypertension (HT) was $4.7 \%$ for boys and $3.2 \%$ for girls, respectively. Children with pre-HT and HT had significantly higher body weight, height, WC, BMI, SBP, DBP, TG, and TC/HDL-C levels but lower HDL-C levels than those children with normotension. After controlling for age, sex, glucose and lipid parameters, child obesity was significantly associated with pre-HT and $\mathrm{HT}$ (odds rations $(\mathrm{ORs})=9.00,95 \% \mathrm{Cl}: 3.20-25.31$ for pre-HT and ORs $=10.60,95 \% \mathrm{Cl}: 3.75-30.00$ for HT). So also was WC (abdominal obesity) when considered alone (ORs $=6.20,95 \% \mathrm{Cl}$ : 2.60-14.81 for pre-HT and ORs $=13.73$, 95\% Cl: 4.85-38.83 for HT) ( $p$-value < 0.001).
\end{abstract}

Conclusions: Obesity among school children was positively associated with higher BP. Prevention of childhood obesity should be strengthened to prevent the risk of early high BP including cardiovascular risk factors.

Keywords: Child obesity, High blood pressure, School children, Waist circumference

\section{Background}

Childhood obesity based on body mass index (BMI) has dramatically increased over the past 3 decades in both developed and developing countries [1] together with many of its health consequences such as dyslipidemia, high blood pressure (BP), abnormal plasma glucose levels and metabolic disorders [2-4]. These are the cardiovascular risk factors that start from childhood and may continue

\footnotetext{
* Correspondence: chutimabk@yahoo.com

'Department of Nutrition, Faculty of Public Health, Mahidol University, 420/1 Rajvithi Road, Rajthevi distric, Bangkok 10400, Thailand

Full list of author information is available at the end of the article
}

into adulthood [5] to become a public health concern in various countries [6]. In Thailand, studies of obesity prevalence in children aged 6-12 years from a National Health Examination Survey using weight-for-height criteria [7] revealed that overweight and obese children increased nationally from $5.8 \%$ in 1997 to $6.7 \%$ in 2001 and then became substantially higher at $8.7 \%$ in 2010 , with the highest regional prevalence (14.8\%) in Bangkok [8]. In 2004, the Bright and Healthy Thai Kid (BAHT) project was launched in 4 Bangkok public schools with the aim of reducing childhood obesity, and the reported baseline 
prevalence of obesity and high blood cholesterol in the study group was $19.3 \%$ and $40 \%$, respectively [2]. Several studies have proposed an association between obesity and high blood pressure, including increased cardiovascular risk factors $[9,10]$. However, current data in Thailand regarding this association are limited, particularly for children. This study aimed to determine the prevalence of obesity and its association with high blood pressure among primary school children.

\section{Methods}

\section{Research design}

This was a cross-sectional study that was conducted during May-July 2012 in Bangkok primary public schools in central Thailand.

\section{School selection}

From four public schools in Bangkok Metropolis under the Office of Basic Education (OBEC) and included in the earlier BAHT project, two were randomly selected. Both schools were coeducational, and had similar demographics for number of students (more than 700 students), gender, school environment, family socioeconomic status (low to middle class) [2] and parental support. Moreover, administrators of both schools were willing to support and participate in the study.

\section{Participants}

Participants were students in grades 3-6 aged 8-12 years during the 2012 academic year and they voluntarily joined this study. The sample size (n) was determined by the Cochran formula [11] :

$$
n=\frac{Z^{2} p q}{e^{2}}
$$

where $Z$ is the standard $Z$ score at $\alpha / 2=0.025, Z=1.96$, where the proportion (p) of childhood obesity was estimated from a previous study [2] in primary schools as 0.193 so that $\mathrm{q}$ was calculated as $\mathrm{q}=1-\mathrm{p}=0.807$ and where the error e at 0.05 was taken from the same study. This yielded a total minimum sample of 240 children.

Informed consent and assent forms were obtained from 63\% (a total of 693 students with 317 boys and 376 girls) and their parents. The proposal was reviewed and approved by the Institutional Review Board, Faculty of Public Health, Mahidol University (Proof No. 100/2555 MUPH 2012-132).

\section{Data collection}

\section{Anthropometric assessment of weight, height and waist} circumference

Weight was measured in kilograms with one decimal point using an electronically calibrated scale (Seca, German) and height was measured in centimeters with one decimal point using a calibrated stadiometer (Microtoise) according to standard measurement procedures [12]. Age and sex specific BMI percentiles for each child were calculated based on the 2000 Centers for Disease Control and Prevention growth charts [13]. Child nutritional status was categorized based on BMI percentile criteria as follows: $<5^{\text {th }}$ percentile for underweight, $\geq 5^{\text {th }}$ but $<85^{\text {th }}$ percentiles for normal, $\geq 85^{\text {th }}$ but $<95^{\text {th }}$ percentiles for overweight: and $\geq 95^{\text {th }}$ percentile for obese, respectively [13] (see details in Additional file 1: 1.1 Child nutritional status). WC was measured at the umbilicus level at exhale using a non-elastic tape with participants in a standing position [14]. The mean of three measurements was used for this analysis. The WC cutoff for age- and sex specific abdominal obesity was defined as the $75^{\text {th }}$ percentile $\left(\mathrm{P}_{75}\right)$ or greater (Additional file 2 ).

\section{Clinical assessment of blood pressure (BP)}

$\mathrm{BP}$ was measured by two trained research assistants in the morning on the left arm of participants in a sitting position after resting at least 5 minutes [15]. The cuff size was based on arm length and circumference of the upper arm of participants $(17 \times 22$ and $22 \times 32 \mathrm{~cm})$. Three measurements at intervals 2-5 minutes apart were obtained by using an automatic blood pressure monitor "Microlife BPA100 model" (Microlife AG, Widnau, Switzerland) [16]. An average of the second and third values was used in the analysis [17].

SBP and DBP percentiles were calculated according to sex, age and height percentile based on the 2000 CDC growth chart and on the fourth report on diagnosis, evaluation, and treatment of high BP in children and adolescents from the national high blood pressure education program working group on high BP in children and adolescents [18]. $\mathrm{BP}$ status was classified according to SBP and/or DBP as follows: $<90^{\text {th }}$ percentile for normal SBP and/or $\mathrm{DBP}, \geq 90^{\text {th }}$ but $<95^{\text {th }}$ percentile for pre-hypertension, and $\geq 95^{\text {th }}$ percentile for hypertension [18] (see details in Additional file 1: 1.2 Child blood pressure classification).

\section{Biochemical assessment}

Participants were instructed to fast after 20:00 h. (10-12 hours). A fasting venous blood sample of 5-7 milliliters from each participant was collected in the morning before breakfast. Blood samples were kept in an ice-box (temperature $4^{\circ} \mathrm{C}$ ) and sent to the Office of Public Health and Environment Technology Services (OPHETS) laboratory, Faculty of Public Health, Mahidol University for automated analysis of FPG and lipid profiles (TC, TG, LDL-C, HDL-C) by the enzymatic method (Beckman Coulter, AU680). The average coefficient of variation for within runs/between days in precision of FPG, TC, TG and HDL-C were 1.05\%/ $2.3 \%, 1 \% / 1.45 \%, 1.2 \% / 2.15 \%$ and $0.65 \% / 1.4 \%$, respectively. 


\begin{tabular}{|c|c|c|c|c|}
\hline Variables & $\begin{array}{c}\text { Total }(\mathrm{N}=693) \\
\bar{X} \pm \mathrm{SD}\end{array}$ & $\begin{array}{c}\text { Male }(\mathrm{n}=\mathbf{3 1 7}) \\
\bar{X} \pm \mathrm{SD}\end{array}$ & $\begin{array}{c}\text { Female }(\mathrm{n}=376) \\
\bar{X} \pm \text { SD }\end{array}$ & p-value \\
\hline Age (years) & $10.34 \pm 1.15$ & $10.29 \pm 1.16$ & $10.39 \pm 1.14$ & 0.24 \\
\hline Weight (kg) & $38.82 \pm 12.50$ & $39.85 \pm 13.71$ & $37.95 \pm 11.33$ & 0.05 \\
\hline Height (cm) & $140.88 \pm 10.33$ & $140.09 \pm 9.96$ & $141.55 \pm 10.60$ & 0.064 \\
\hline BMI $\left(\mathbf{k g} / \mathrm{m}^{2}\right)$ & $19.19 \pm 4.47$ & $19.85 \pm 4.90$ & $18.63 \pm 4.00$ & $<0.001$ \\
\hline WC (cm) & $70.35 \pm 12.05$ & $72.28 \pm 13.43$ & $68.73 \pm 10.50$ & $<0.001$ \\
\hline SBP $(\mathrm{mmHg})$ & $101.43 \pm 11.33$ & $103.16 \pm 11.98$ & $99.96 \pm 10.55$ & $<0.001$ \\
\hline $\mathrm{DBP}(\mathrm{mmHg})$ & $60.06 \pm 7.41$ & $60.51 \pm 7.65$ & $59.69 \pm 7.20$ & 0.149 \\
\hline FPG (mg/dl) & $88.15 \pm 5.67$ & $88.87 \pm 5.55$ & $87.55 \pm 5.71$ & 0.002 \\
\hline TC (mg/dl) & $182.18 \pm 30.58$ & $179.00 \pm 30.27$ & $184.85 \pm 30.62$ & 0.012 \\
\hline TG (mg/dl) & $84.28 \pm 42.46$ & $78.38 \pm 40.56$ & $89.26 \pm 43.43$ & 0.001 \\
\hline LDL (mg/dl) & $105.24 \pm 27.03$ & $102.79 \pm 25.66$ & $107.30 \pm 28.00$ & 0.028 \\
\hline HDL (mg/dl) & $60.08 \pm 11.95$ & $60.53 \pm 11.91$ & $59.69 \pm(11.99$ & 0.358 \\
\hline TC/HDL-C & $3.12 \pm 0.69$ & $3.03 \pm 0.60$ & $3.20 \pm 0.75$ & 0.002 \\
\hline
\end{tabular}

Data are presented as means \pm SD. Univariate analyses were calculated by t-test. BMI, body mass index; WC, waist circumference; SBP, systolic blood pressure; DBP, diastolic blood pressure; FPG, Fasting plasma glucose level; TC, total cholesterol level; TG, triglyceride level; LDL-C, low-density lipoprotein cholesterol level; $\mathrm{HDL}-\mathrm{C}$, high-density lipoprotein cholesterol level.

\section{Statistical analyses}

All the data were analyzed using Predictive Analytics Software for Windows (PASW) version 18. Continuous variables (age, weight, height, BMI, WC, SBP, DBP, FPG, TC, TG, LDL-C, HDL-C and TC/HDL-C) were used to describe general characteristics of children with mean and standard deviation (SD) and the means were compared for gender differences using a Student t-test. The categorical variables for age- and sex-specific BMI and $\mathrm{WC}$ as numbers and percentages were compared using $\chi^{2}$ analysis. Analysis of covariance (ANCOVA) was used to compare the mean difference of anthropometric measurements, blood sugar level and lipid parameters among BP status. Multiple regression was used to examine the association of SBP and DBP with BMI and WC, controlling for other covariates including age, sex, plasma glucose and lipid parameters. Multinomial logistic regression was used to examine the association between BP status $(0=$ normotension, 1 = pre-hypertension, and 2 =hypertension) as dependent variables with nutritional status adjusted for the covariate variables including age, sex, plasma glucose and lipid levels. Odds ratios and 95\% confidence intervals (95\% CI) were determined. Differences with p-values $\leq$ 0.05 were considered to be statistically significant.

\section{Results}

The study included a total of 693 participants (317 boys and 376 girls) whose mean ages were 10.29 (boys) and 10.39 (girls). General characteristics, anthropometric data, FPG and lipid profile of the participants are presented in Table 1. Boys had significantly higher BMI, WC, SBP and
FPG levels than girls ( $\mathrm{p}$-values < 0.001). However, girls had significantly higher TC, TG, LDL-C, and TC/HDL-C levels than boys ( $p$-values $<0.001$ ). There were no statistically significant differences in average height, DBP and HDL-C levels. Prevalence of obesity was $30.6 \%$ in the boys and $12.8 \%$ in the girls (mean for both $20.9 \%$ ) (Figure 1). Prevalence of pre-HT was $5.4 \%$ for boys and $2.7 \%$ for girls and HT was $4.7 \%$ and $3.2 \%$ for boys and girls, respectively (Figure 2). In Table 2, the prevalence of pre-HT and $\mathrm{HT}$ was $13.1 \%$ and $13.8 \%$ for obese children and $10.5 \%$ and $12.9 \%$, for children when considering WC (abdominal obesity) alone. All these prevalences were significantly higher than those of non-obese children (p-value <0.001).

Table 3 shows that children with pre-HT and HT had significantly higher body weight, height, WC, BMI, SBP, DBP, TG, and TC/HDL-C levels but lower HDL-C levels

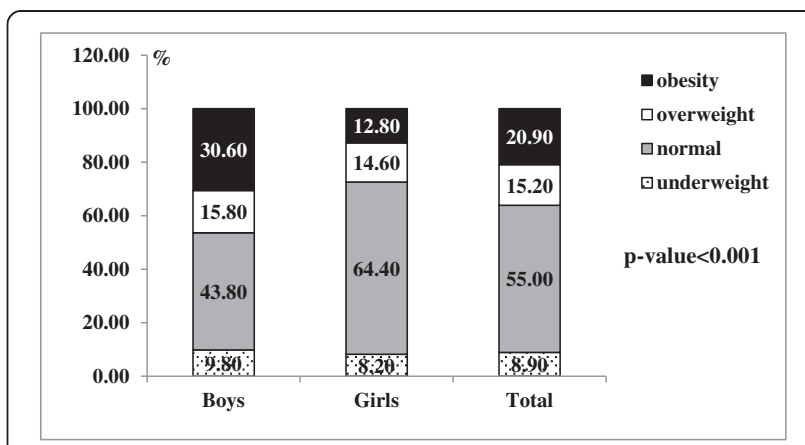

Figure 1 Nutritional status using BMI for age among school children. 


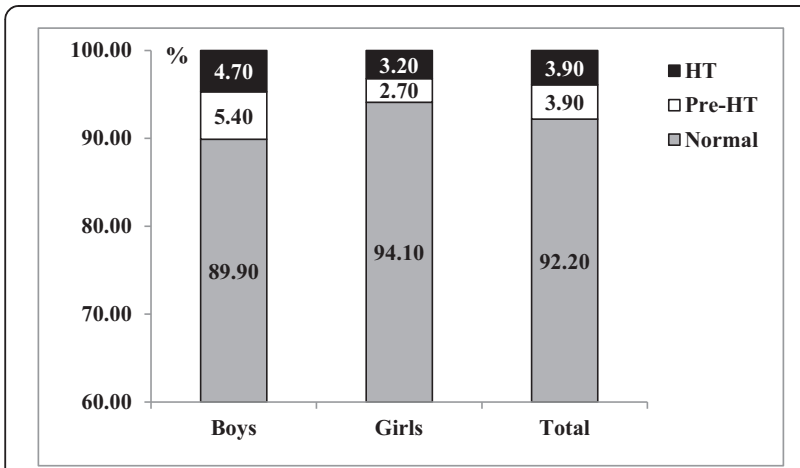

Figure 2 Prevalence of pre-hypertension and hypertension among school children.

than children with normotension. There was no significant difference in the mean of FPG, TC and LDL-C levels after controlling for gender and age.

Table 4 presents the results from multiple regression analysis for association between $\mathrm{BP}$ and $\mathrm{BMI} / \mathrm{WC}$ controlling for all covariates. FPG, BMI and WC were significantly associated with SBP and DBP. The association of high blood pressure and obesity status (BMI and WC) after controlling for sex, age, plasma glucose and lipid levels is shown in Table 5. Using the normal BMI for age as reference, the adjusted odds ratios for pre-HT and HT risk from obesity were 9.00 (95\% CI, 3.20-25.31) and 10.60 (95\% CI, 3.75-30.00) after adjusting for gender, age, plasma glucose and lipid values. Likewise, the adjusted odds ratios for pre-HT and HT for WC (abdominal obesity) alone were 6.20 (95\% CI: 2.60-14.81) and 13.73 (95\% CI: 4.85-38.83).

\section{Discussion}

Our findings revealed that anthropometric measures (weight, height, BMI and WC) and biochemical measurements of TG and TC/HDL levels among children with preHT and HT were significantly higher than those among children with normotension. This indicated that obese children showed a significantly higher prevalence of preHT and HT than non-obese children.

Our mean prevalence for obesity at $20.9 \%$ in two schools was higher than the national prevalence reported by the Thailand National Health examination survey as $6.7 \%$ in
2001 and as $8.7 \%$ in 2010 [7], with the highest regional prevalence of $14.8 \%$ in Bangkok [8]. The latter was similar to the finding of the Shanghai CDC that reported the prevalence of child obesity as $13.5 \%$ in 2009 [19]. Our higher prevalence of obesity than the Thai national prevalence may have been the result of using the CDC growth chart, since Thai children categorized as obese had greater weight but relatively shorter stature when compared to American children of the same age and sex. This would result in relatively high BMI or obesity rates. On the other hand, the mean prevalence of obesity (20.9\%) in our study group was lower than that reported for children from the US at $31.0 \%$ [20] but the same as that reported by the South Carolina Pediatric Practice Research Network at $21.7 \%$ [21].

Our study revealed that obesity prevalence for boys was over $30 \%$ while that for girls was almost three times less at $12 \%$. Similar results have been reported from China [22] and Taiwan [23]. We did not collect data amenable to analysis for a possible explanation regarding this difference. Neither was an explanation given in the cited studies from China and Taiwan. Therefore, we must resort solely to speculation regarding possibilities. In a previous report [2], it was explained that the overall increase in obesity in Thai children may have been encouraged by a traditional positive attitude that overweight children are healthy and cute and by subsequent overindulgence, especially in small families. However, these are overall factors that may not apply evenly to boys and girls. For example, it is possible that girls are subjected to social and media pressure to be slim and shapely while boys are not, and this may result in some measure of weight control motivation that is present in girls but not in boys. To obtain an answer to such speculation, a more sophisticated motivational study than ours would be required.

WC is an indicator of distribution of abdominal or visceral fat, and also is an indicator for insulin resistance, type 2 diabetes, dyslipidemia and cardiovascular disease in the form of high blood pressure in childhood and adulthood [24]. Because the WC cutoff for abdominal obesity varies among different populations [25] and because a Thai reference standard is still lacking, we used a cutoff at $\mathrm{P}_{75}$ for screening cardiovascular risks in our children. This cutoff at $\mathrm{P}_{75}$ is similar to one of the cutoffs used for

Table 2 Prevalence of pre-hypertension and hypertension by BMI for age and WC among school children

\begin{tabular}{|c|c|c|c|c|c|c|c|c|}
\hline \multirow[t]{2}{*}{ Criteria } & \multicolumn{4}{|c|}{ BMI for age and gender } & \multirow[t]{2}{*}{ p-value } & \multicolumn{2}{|c|}{ WC } & \multirow[t]{2}{*}{ p-value } \\
\hline & Under weight & Normal & Over weight & Obese & & $<P_{75}$ & $\geq P_{75}$ & \\
\hline Normal & $62(100.0)$ & $375(96.9)$ & $102(97.1)$ & $106(73.1)$ & $<0.001$ & $508(97.3)$ & $131(76.6)$ & $<0.001$ \\
\hline Pre-hypertension & $0(0.0)$ & $6(1.6)$ & $2(1.9)$ & $19(13.1)$ & & $9(1.7)$ & $18(10.5)$ & \\
\hline Hypertension & $0(0.0)$ & $6(1.6)$ & $1(1.0)$ & $20(13.8)$ & & $5(1.0)$ & $22(12.9)$ & \\
\hline
\end{tabular}

Data are presented as $\mathrm{n}(\%)$ and were calculated by $\chi^{2}$ test. SBP, systolic blood pressure and DBP, diastolic blood pressure $\geq \mathrm{P}_{90}$ but less than $\mathrm{P}_{95}$ was defined as pre-hypertension; $\geq \mathrm{P}_{95}$ was defined as hypertension with boys and girls. 
Table 3 Age and sex-adjusted means of anthropometric and lipid measures by blood pressure among school children

\begin{tabular}{|c|c|c|c|c|}
\hline \multirow[t]{3}{*}{ Variables } & \multicolumn{3}{|c|}{ Blood pressure criteria } & \multirow[t]{3}{*}{ p-value } \\
\hline & Normotension $(n=639)$ & Pre-hypertension $(n=27)$ & Hypertension $(n=27)$ & \\
\hline & $\bar{X}(\mathrm{SE})$ & $\bar{X}(\mathrm{SE})$ & $\bar{X}(\mathrm{SE})$ & \\
\hline Weight (kg) & $37.76^{\mathrm{a}, \mathrm{b}}(0.42)$ & $49.23^{\mathrm{a}}(2.05)$ & $53.47^{\mathrm{b}}(2.05)$ & $<0.001$ \\
\hline Height (cm) & $140.61^{\mathrm{b}}(0.28)$ & $143.95(1.35)$ & $144.38^{\mathrm{b}}(1.35)$ & 0.002 \\
\hline BMI $\left(\mathrm{kg} / \mathrm{m}^{2}\right)$ & $18.76^{\mathrm{a}, \mathrm{b}}(0.16)$ & $23.43^{\mathrm{a}}(0.79)$ & $25.21^{\mathrm{b}}(0.79)$ & $<0.001$ \\
\hline WC (cm) & $69.17^{\mathrm{a}, \mathrm{b}}(0.43)$ & $82.36^{\mathrm{a}}(2.11)$ & $86.42^{b}(2.11)$ & $<0.001$ \\
\hline SBP $(\mathrm{mmHg})$ & $99.64^{\mathrm{a}, \mathrm{b}}(0.36)$ & $118.91^{\mathrm{a}, \mathrm{c}}(1.75)$ & $126.20^{b, c}(1.75)$ & $<0.001$ \\
\hline DBP (mmHg) & $59.15^{\mathrm{a}, \mathrm{b}}(0.26)$ & $70.00^{\mathrm{a}}(1.28)$ & $71.71^{b}(1.28)$ & $<0.001$ \\
\hline FPG (mg/dl) & $88.02(0.22)$ & $90.46(1.07)$ & $89.00(1.07)$ & 0.06 \\
\hline $\mathrm{TC}(\mathrm{mg} / \mathrm{dl})$ & $182.29(1.21)$ & $180.71(5.88)$ & $180.96(5.87)$ & 0.95 \\
\hline TG (mg/dl) & $82.29^{\mathrm{a}, \mathrm{b}}(1.64)$ & $105.46^{\mathrm{a}}(8.02)$ & $110.40^{\mathrm{b}}(8.00)$ & $<0.001$ \\
\hline LDL-C (mg/dl) & $105.14(1.07)$ & $107.21(5.20)$ & $105.56(5.19)$ & 0.93 \\
\hline HDL-C (mg/dl) & $60.69^{a, b}(0.47)$ & $52.36^{\mathrm{a}}(2.27)$ & $53.23^{\mathrm{b}}(2.27)$ & $<0.001$ \\
\hline TC/HDL-C & $3.09^{a, b}(0.03)$ & $3.50^{\mathrm{a}}(0.13)$ & $3.50^{\mathrm{b}}(0.13)$ & $<0.001$ \\
\hline
\end{tabular}

Values are presented as mean(SE). Mean difference was analyzed by ANCOVA adjusted age and gender.

Means in row with superscript letter differ as defined pos hoc analysis.

${ }^{a}$ The significant difference between normal (normotension) and pre-hypertension ( $p$-value $<0.05$ ).

${ }^{b}$ The significant difference between normal and hypertension ( $p$-value $<0.05$ ).

'The significant difference between pre-hypertension and hypertension ( $p$-value $<0.05$ )

abdominal obesity screening for cardiovascular risks in Chinese children [25].

The high prevalence of overweight/obesity among schoolaged children in this study might be due to less physical activity and higher consumption of more unhealthy, highfat foods, sweetened beverages and salty snacks and less milk, fruits and vegetables than recommended $[2,3,26]$. Various studies have shown that dietary intake, physical activity and self-discipline are major factors influencing obesity and high blood pressure [1-3,27].
Lipid profiles of girls were significantly higher than those of boys, as reported in other studies [28,29] where this was suggested to result primarily from poor eating habits and low physical activity and to be independent of nutritional status. In a previous study [3] it was reported that a high intake of cholesterol and saturated fatty acids originated from popular diets such as fried chicken, sausages and cakes that are high in saturated fatty acids and cholesterol that influence TC and LDL-C levels. In addition to fats, favorite snacks tend to be high also in

Table 4 Multiple regression for association between obesity/waist circumference and blood pressure including all covariates

\begin{tabular}{|c|c|c|c|c|}
\hline \multirow[t]{2}{*}{ Variables } & \multicolumn{2}{|c|}{ SBP } & \multicolumn{2}{|c|}{ DBP } \\
\hline & Model $1 \beta$ (SE) & Model $2 \beta$ (SE) & Model $3 \beta$ (SE) & Model $4 \beta$ (SE) \\
\hline Constant & $50.98^{* *}(5.80)$ & $44.00^{* *}(5.70)$ & $34.05^{* *}(4.37)$ & $30.74^{* *}(4.37)$ \\
\hline Age & $0.94^{* *}(0.30)$ & $0.66^{*}(0.29)$ & $0.36(0.23)$ & $0.23(0.23)$ \\
\hline Sex & $-1.37(0.70)$ & $-1.02(0.68)$ & $1.44(0.52)$ & $0.30(0.52)$ \\
\hline FPG & $0.15^{*}(0.06)$ & $0.13^{*}(0.06)$ & $0.11^{*}(0.05)$ & $0.10^{*}(0.05)$ \\
\hline TG & $0.01(0.01)$ & $0.01(0.01)$ & $0.01(0.01)$ & $0.01(0.01)$ \\
\hline LDL-C & $-0.01(0.02)$ & $-0.01(0.02)$ & $0.04(0.01)$ & $0.003(0.01)$ \\
\hline $\mathrm{TC} / \mathrm{HDL}-\mathrm{C}$ & $-0.21(0.88)$ & $-0.35(0.85)$ & $-0.35(0.85)$ & $-0.91(0.65)$ \\
\hline BMl & $1.47^{* *}(0.09)$ & - & $0.71^{* *}(0.06)$ & - \\
\hline WC & - & $0.58 * *(0.03)$ & - & $0.28^{* *}(0.02)$ \\
\hline$R^{2}$ & 0.41 & 0.44 & 0.22 & 0.23 \\
\hline
\end{tabular}

Model 1; age, sex, FPG, TG, LDL-C, TC/HDL-C and BMI. Model 2; age, sex, FPG, TG, LDL-C, TC/HDL-C and WC. Model 3; age, sex, FPG, TG, LDL-C, TC/HDL-C and BMI. Model 4; age, sex, FPG, TG, LDL-C, TC/HDL-C and WC. ${ }^{*}$ p-value $<0.05 ;{ }^{* *}$-value $<0.01$. 
Table 5 Multinomial logistic regression adjusted odds ratios for association between BMI/ WC and blood pressure

\begin{tabular}{lcc}
\hline Variables & Pre-hypertension & Hypertension \\
\hline BMI for age and gender & & \\
- Normal & Reference group & Reference group \\
- Overweight & $1.05(0.20-5.50)$ & $0.50(0.06-4.42)$ \\
- Obesity & $9.00^{* *}(3.20-25.31)$ & $10.60^{* *}(3.75-30.00)$ \\
WC & & \\
- <P75 & Reference group & Reference group \\
- $\geq$ P75 & $6.20^{* *}(2.60-14.81)$ & $13.73^{* *}(4.85-38.83)$ \\
\hline
\end{tabular}

Multinomial logistic regression was computed for high blood pressure risk factors controlling age, sex, plasma lipid (TG and TC/HDL-C) and glucose (FPG) levels. Values were reported as odd ratio (OR) and $95 \%$ confidence intervals $(95 \% \mathrm{Cl})$. ${ }^{* *}$-value $<0.01$.

carbohydrates and salt. Excess carbohydrates can be changed to TG [30] and this may be reflected in the higher TG levels.

Obese children showed a statistically significant higher prevalence of pre-hypertension and hypertension than non-obese children, and this was similar to findings from other studies $[9,19]$. The finding of HT prevalence at $13.8 \%$ in the present study was lower than that found in Canadian and Chinese children $(19.5 \%$ and $25.6 \%$, respectively). The mean levels of FPG, TC and LDL-C were not significantly different among the three BP groups, a result similar to that reported in a study by Boyd et al. [10]. Plasma glucose, obesity and WC (abdominal obesity) alone were associated with SBP and DBP by multiple regression analysis, but there was no association of lipid profiles with SBP and DBP. However, previous studies have reported that plasma glucose and lipids are correlated with blood pressure linked to metabolic syndromes [10,31].

Overall, our study revealed that there were positive associations between high SBP/DBP and BMI or WC alone after adjusting for age, gender, FPG and lipids levels. These results were similar to those of previous studies indicating that high blood pressure increased with increasing BMI and WC after adjusting for age and sex [19,32]. These findings suggest that obese children are at higher risk of having high blood pressure than normal children. Therefore, obese children should be routinely screened for blood pressure and other coexisting cardiovascular risk factors including lipid profile $[3,33]$. In addition, healthy lifestyles should be encouraged by schools and at home since prevention in childhood can help to avoid undesirable health consequences in the future [2,4].

Limitations of our study include of the following. First, our research was a cross-sectional study that cannot explain the causal relationships between high blood pressure and obesity. Second, blood pressure was measured on a single occasion and would be more accurate if confirmed on several occasions. Finally, the sample size for the obese group was quite small when compared with the reference group, leading to the wide range of $95 \% \mathrm{CI}$. Hence, a larger study to confirm the precision of the association might be needed.

\section{Conclusions}

This study revealed that obesity was positively and significantly associated with higher blood pressure. Therefore, development of healthy lifestyle practices should be encouraged from childhood in schools and at home to prevent and control future undesirable cardiovascular consequences.

\section{Additional files}

Additional file 1: 1.1 Child nutritional status. 1.2 Child blood pressure classification.

Additional file 2: The $75^{\text {th }}$ percentile for age-and sex- specific waist circumference (WC) cut-off points.

\section{Abbreviations}

BMI: Body mass index; Cl: Confidence Interval; DBP: Diastolic blood pressure; FPG: Fasting plasma glucose; HDL-C: High density lipoprotein-cholesterol; HT: Hypertension; LDL-C: Low density lipoprotein-cholesterol; OBEC: Office of the Basic Education Commission; OR: Odds ratios; P: Percentile; pre-HT: Pre-hypertension; SBP: Systolic blood pressure; SD: Standard deviation; TC: Total cholesterol; TG: Triglyceride; WC: Waist circumference.

\section{Competing interests}

The authors declare that they have no competing interests.

\section{Authors' contributions}

PS was the principal investigator. CS was the project manager, initiated the concept of the study, obtained research grant support, coordinated the research, assigned individual roles of participants and was responsible for overall supervision. PS, WA, CH and CS made contributions to the design of the study. PS was involved in the literature review and data collection. PS and WA made contributions in analysis and interpretation of the data, and drafting of the manuscript. CS revised the content and approved the manuscript. All authors read and approved the final manuscript.

\section{Funding}

This study was supported by the Office of Higher Education Commission (OHEC) under the program Strategic Scholarships Fellowships Frontier Research Networks (Specific for Southern Region) and was partially supported for data collection and publication from the China Medical Board of New York (CMB), Faculty of Public Health, Mahidol University Bangkok, Thailand and the Thai Health Promotion Foundation. The authors would like to thank all school children and their caregivers for kindly cooperating in the study. We would also like to thank T.W. Flegel for assistance with editing the manuscript.

\section{Author details}

'Department of Nutrition, Faculty of Public Health, Mahidol University, 420/1 Rajvithi Road, Rajthevi distric, Bangkok 10400, Thailand. ${ }^{2}$ Department of Community Medicine, Faculty of Medicine, Ramathibodi Hospital, Mahidol University, 270 Rama VI Road, Rajthevi district, Bangkok 10400, Thailand.

Received: 2 February 2014 Accepted: 10 July 2014

Published: 18 July 2014

\section{References}

1. Dehghan M, Akhtar-Danesh N, Merchant AT: Childhood obesity, prevalence and prevention. Nutr J 2005, 4:24. 
2. Sirikulchayanonta C, Pavadhgul P, Chongsuwat R, Klaewkla J: Participatory action project in reducing childhood obesity in Thai primary schools. Asia Pac J Public Health 2010, 10:1-11.

3. Sirikulchayanonta C, Pavadhgul P, Chongsuwat R, Srisorrachata S: A preliminary study of hyperlipidemia in Bangkok school children. Asia Pac J Public Health 2006, 18:15-19.

4. Falkner B, Lurbe E, Schaefer F: High Blood Pressure in Children: Clinical and Health Policy Implications. J Clin Hypertens 2010, 12:261-276.

5. Chen $X$, Wang Y: Tracking of blood pressure from childhood to adulthood: A systematic review and meta-regression analysis. Circulation 2008, 117:3171-3180

6. Kearney PM, Whelton M, Reynolds K, Muntner P, Whelton PK, He J: Global burden of hypertension: analysis of worldwide data. Lancet 2005, 365:217-223.

7. Aekplakorn W, Mo-suwan L: National prevalence of obesity: Prevalence of obesity in Thailand. Obes Rev 2009, 10:589-592.

8. Mo-suwan L: Nutrional status in children. In The Forth National Health Examination Survey in 2008-2009: Children Healths. Edited by Aekplakorn W. Bangkok: The Graphico Systems Co., Ltd; 2010:103-126.

9. Salvadori M, Sontrop JM, Garg AX, Truong J, Suri RS, Mahmud FH, Macnab $\mathrm{J}$, Clark WF: Elevated blood pressure in relation to overweight and obesity among children in a rural Canadian community. Pediatrics 2008, 122:e821-e827.

10. Boyd GS, Koenigsberg J, Falkner B, Gidding S, Hassink S: Effect of obesity and high blood pressure on plasma lipid levels in children and adolescents. Pediatrics 2005, 116:442-446.

11. Cochran WG: Sampling Techniques. 3rd edition. New York: John Wiley\& Sons; 1977

12. Gibson RS: Anthropometric assessment of body size. In Principles of Nutritional Assessment. 2nd edition. Edited by Gibson RS. New York: Oxford University Press; 2005:247-253.

13. Center for Disease Control and Prevention and National Center for Health Statistics: 2000 CDC Clinical Growth Charts. [http://www.cdc.gov/growthcharts/ clinical_charts.htm]

14. McCarthy HD, Jarret KV, Crawley HF: The development of waist circumference percentiles in British children aged 5.0-16.9 y. Eur J Clin Nutr 2001, 55:902-907.

15. Pickering TG, Hall JE, Appel LJ, Falkner BE, Graves JW, Hill MN, Jones DH, Kurtz T, Sheps SG, Roccella EJ: Recommendations for blood pressure measurement in humans: an AHA scientific statement from the Counci on High Blood Pressure Research Professional and Public Education Subcommittee. J Clin Hypertens (Greenwich) 2005, 7:102-109.

16. Bonso E, Dorigatti F, Palatini P: Accuracy of the BP A100 blood pressure measuring device coupled with a single cuff with standard-size bladder over a wide range of arm circumferences. Blood Press Monit 2009, 14:216-219.

17. Aekplakorn W, Sangthong R, Kessomboon P, Putwatana P, Inthawong R, Taneepanichskul S, Sritara P, Sangwatanaroj S, Chariyalertsak S: Changes in prevalence, awareness, treatment and control of hypertension in Thai population, 2004-2009: Thai National Health Examination Survey III-IV. J Hypertens 2012, 30:1734-1742.

18. National High Blood Pressure Education Program Working Group on High Blood Pressure in Children and Adolescents: The fourth report on the diagnosis, evaluation, and treatment of high blood pressure in children and adolescents. Pediatrics 2004, 114:555-576.

19. Lu X, Shi P, Luo C-Y, Zhou Y-F, Yu H-T, Guo C-Y, Wu F: Prevalence of hypertension in overweight and obese children from a large school-based population in Shanghai, China. BMC Public Health 2013, 13:1-7.

20. Ogden CL, Carroll MD, Kit BK, Flegal KM: Prevalence of obesity and trends in body mass index among US children and adolescents, 1999-2010. JAMA 2012, 307:483-490.

21. Roberts JR, Kennedy SA, Darden PM, Basco WT Jr: Prevalence of obesity in children: comparing children from the South Carolina Pediatric Practice Research Network with a national sample. Clin Pediatr 2010, 49:750-755.

22. Pan $H$, Jiang $Y$, Jing $X$, Fu S, Jiang $Y$, Lin Z, Sheng $Z$, Cole TJ: Child body mass index in four cities of East China compared to Western references. Ann Hum Biol 2009, 36:98-109.

23. Chen LJ, Fox KR, Haase A, Wang JM: Obesity, fitness and health in Taiwanese children and adolescents. Eur J Clin Nutr 2006, 60:1367-1375.

24. Ball GD, Huang TT, Cruz ML, Shaibi GQ, Weigensberg MJ, Goran MI: Predicting abdominal adipose tissue in overweight Latino youth. Int J Pediatr Obes 2006, 1:210-216.
25. Ma GS, Ji CY, Ma J, Mi J, Yt Sung R, Xiong F, Yan WL, Hu XQ, Li YP, Du SM, Fang HY, Jiang JX: Waist circumference reference values for screening cardiovascular risk factors in Chinese children and adolescents. Biomed Environ Sci 2009, 22:269-277.

26. Satheannoppakao W: Eating behaviors. In The Forth National Health Examination Survey in 2008-2009: Food Consumption of Thai Population. Edited by Aekplakorn W. Bangkok: The Graphico Systems Co., Ltd; 2010:31-71.

27. Sirikulchayanonta C, Ratanopas W, Temcharoen P, Srisorrachatr S: Self discipline and obesity in Bangkok school children. BMC Public Health 2011, 11:158.

28. Guillaume M, Lapidus L, Lambert A: Differences in associations of familial and nutritional factors with serum lipids between boys and girls: the Luxembourg Child Study. Am J Clin Nutr 2000, 72:384-388.

29. Magkos F, Piperkou I, Manios Y, Papoutsakis C, Yiannakouris N, Cimponerio A, Aloumanis K, Skenderi K, Papathoma A, Arvaniti F, Sialvera TE, Christou D, Zampelas A: Diet, blood lipid profile and physical activity patterns in primary school children from a semi-rural area of Greece. J Hum Nutr Diet 2006, 19:101-112.

30. Parks EJ: Effect of dietary carbohydrate on triglyceride metabolism in humans. J Nutr 2001, 131:2772S-2774S.

31. Invitti C, Gilardini L, Pontiggia B, Morabito F, Mazzilli G, Viberti G: Period prevalence of abnormal glucose tolerance and cardiovascular risk factors among obese children attending an obesity centre in Italy. Nutr Metab Cardiovasc Dis 2006, 16:256-262.

32. Hu YH, Reilly KH, Liang YJ, Xi B, Liu JT, Xu DJ, Yan YK, Xie B, Li XY: Increase in body mass index, waist circumference and waist-to-height ratio is associated with high blood pressure in children and adolescents in China. J Int Med Res 2011, 39:23-32.

33. Pearson TA, Palaniappan LP, Artinian NT, Carnethon MR, Criqui MH, Daniels SR, Fonarow GC, Fortmann SP, Franklin BA, Galloway JM, Goff DC Jr, Heath GW Frank AT, Kris-Etherton PM, Labarthe DR, Murabito JM, Sacco RL, Sasson C, Turner MB: American Heart Association guide for improving cardiovascular health at the community level, 2013 update: A scientific statement for public health practitioners, healthcare providers, and health policy makers. Circulation 2013, 127:1730-1753.

doi:10.1186/1471-2458-14-729

Cite this article as: Sukhonthachit et al:: The association between obesity and blood pressure in Thai public school children. BMC Public Health 2014 14:729.

\section{Submit your next manuscript to BioMed Central and take full advantage of:}

- Convenient online submission

- Thorough peer review

- No space constraints or color figure charges

- Immediate publication on acceptance

- Inclusion in PubMed, CAS, Scopus and Google Scholar

- Research which is freely available for redistribution 